\title{
Manejo da adubação potássica e da irrigação no progresso de doenças fúngicas e produtividade da melancia
}

\author{
Gil R dos Santos; Evelynne U Leão; Clebson G Gonçalves; Carlos H Cardon
}

UFT, Produção Vegetal, C. Postal 66,77402-970 Gurupi-TO; gilrsan@mail.uft.edu.br; evelynnegpi@hotmail.com; goncalvescg.agro@, hotmail.com; cardon-2007@hotmail.com

\section{RESUMO}

Entre as principais doenças da melancia, o crestamento gomoso do caule (Didymella bryoniae) e o míldio (Pseudoperonospora cubensis) se destacam devido às grandes perdas que causam na produtividade e qualidade de frutos. Para investigar a influência da adubação potássica no progresso do crestamento gomoso e na produtividade da melancia e a influência da lâmina de água e do intervalo de irrigação no progresso do míldio, foram conduzidos dois ensaios em condições de campo em Gurupi-TO, nos anos de 2009 e 2010. O ensaio I foi conduzido em blocos ao acaso e os tratamentos se constituíram em três doses de potássio aplicadas em cobertura $\left(0,50\right.$ e $100 \mathrm{~kg} \mathrm{ha}^{-1}$ de $\left.\mathrm{KCl}\right)$ e 12 repetições, sendo avaliada a severidade do crestamento gomoso, por meio de uma escala de notas e os dados de produção e qualidade dos frutos. No ensaio II, utilizou-se o delineamento em blocos ao acaso com quatro repetições, em esquema fatorial de $3 \times 3$, três lâminas de irrigação (100, 300 e 500 mm de água durante o ciclo da cultura) e três intervalos de irrigação. Avaliou-se além da severidade do míldio, também a produção e a qualidade dos frutos. Constatou-se que as doses de potássio não influenciaram no progresso do crestamento gomoso e no número, peso médio e qualidade dos frutos. As lâminas de irrigação aplicadas influenciaram no progresso do míldio. Maiores níveis de severidade do míldio foram observados nas plantas mantidas sob irrigação com lâmina de $500 \mathrm{~mm}$ de água. As lâminas de água aplicadas também influenciaram significativamente na produção e qualidade dos frutos. Observou-se a presença de maior número de frutos deformados ou tortos nas plantas mantidas sob déficit hídrico, na lâmina de 100 $\mathrm{mm}$. As maiores produtividades comerciais e totais foram obtidas nas plantas irrigadas com a lâmina de $500 \mathrm{~mm}$ de água.

Palavras-chave: Citrullus lanatus, Didymella bryoniae, Pseudoperonospora cubensis, potássio, regime hídrico.

\begin{abstract}
Potassium fertilizer and irrigation management in the progress of fungal diseases and yield of watermelon
\end{abstract}

Among the major diseases of watermelon, gummy stem blight (Didymella bryoniae) and downy mildew (Pseudoperonospora cubensis) stand out because they cause great losses in productivity and fruit quality. To investigate the influence of potassium fertilization on the progress of gummy stem blight and yield of watermelon and the influence of the water depth and the interval of irrigation in the progress of mildew, two assays were carried out under field conditions in Gurupi, Tocantins state, Brazil, in 2009 and 2010. The assay I was carried out in blocks and the treatments consisted of three doses of potassium applied (0,50 and $100 \mathrm{~kg} / \mathrm{ha}$ using $\mathrm{KCl})$ and 12 replications. We evaluated the severity of gummy stem blight through a scale and the production data and fruit quality. In the assay II, we used a randomized complete block design with four replications in a factorial $3 \times 3$, three irrigation levels $(100,300$ and $500 \mathrm{~mm}$ of water during the crop cycle) and three irrigation intervals. We evaluated the severity of downy mildew addition, the production and fruit quality. Doses of potassium did not affect the progress of gummy stem blight and the number, weight and fruit quality. The irrigation applied influenced the progress of downy mildew. Higher levels of severity of downy mildew were observed in plants cultivated under irrigation with levels of $500 \mathrm{~mm}$ of water. The amount of water applied also significantly influenced the production and fruit quality. We observed the presence of more crooked or deformed fruits in plants kept under water using a level of $100 \mathrm{~mm}$. The highest total and marketable yield were obtained in plants irrigated with the level of $500 \mathrm{~mm}$ of water.

Keywords: Citrullus lanatus, Didymella bryoniae, Pseudoperonospora cubensis, potassium, water regime.

\section{(Recebido para publicação em 27 de outubro de 2011; aceito em 2 de janeiro de 2013) (Received on October 27, 2011; accepted on January 2, 2013)}

\begin{abstract}
A pesar do Brasil se situar entre os países maiores produtores de melancia (Citrullus lanatus) a produtividade é considerada baixa, devido principalmente à ocorrência de doenças fúngicas que reduzem a produtividade e a qualidade dos frutos. Dentre as doenças fúngicas que ocorrem na melancia, o crestamento gomoso do caule, ou cancro da haste, causado pelo fungo Didymella bryoniae, pode ser considerada como uma das principais, pois provoca tombamento
\end{abstract}

das plântulas, lesões nas folhas e formação de cancros no caule e nas hastes, podendo causar grandes perdas na produtividade (Santos \& Café-Filho, 2005; Santos et al., 2005a). O míldio, agente causal Pseudoperonospora cubensis, também é uma doença importante devido ao seu difícil controle e à velocidade de propagação da doença, resultando na rápida desfolha, podendo provocar perdas de até $100 \%$ na produção, principalmente sob chuvas acompanhadas de temperatura amena
(Santos et al., 2010). As medidas de controle adotadas para estas doenças baseiam-se no uso de fungicidas protetores e sistêmicos, cuja eficácia é reduzida em cultivares muito suscetíveis, sob plantios com excesso de umidade ou em condições meteorológicas favoráveis ao patógeno (Santos et al., 2011).

Entre as medidas que podem ser adotadas no manejo das culturas, a fertilização do solo e a irrigação adequada podem ser importantes aliados no controle das doenças. O potássio é 
requerido em grande quantidade pela melancia, sendo a sua exigência superior à do nitrogênio, com uma maior quantidade sendo exigida após o período de frutificação (Cecílio Filho \& Grangeiro, 2004). Este nutriente atua como ativador enzimático de processos responsáveis pela síntese e degradação de compostos orgânicos e participa no processo de abertura e fechamento das células estomatais, síntese de proteína, composição da parede celular e balanço entre cátions e ânions (Malavolta, 2005; Nachtigall \& Raij, 2005). A adubação potássica pode influenciar favoravelmente na produção de frutos de qualidade e com maior tolerância da cultura ao ataque de certas doenças e pragas, além de aumentar a resistência do fruto ao transporte e ao armazenamento (Silva, 2010).

Em relação ao manejo da irrigação, sabe-se que plantas irrigadas apresentam melhor desenvolvimento. Entretanto, o excesso de umidade favorece a infecção pelos patógenos devido à maior duração do molhamento foliar. O manejo da irrigação também influencia na diluição e absorção de nutrientes do solo pela planta, pois a falta de umidade do solo pode condicionar menor absorção de nutrientes e o excesso pode levar à lixiviação destes nutrientes minerais (Gama et al., 2011). No estado do Tocantins e demais regiões produtoras de melancia, o manejo da irrigação é realizado de forma empírica tanto nos plantios em terras altas, como nas várzeas. De acordo com Santos et al. (2004), são raros os produtores que fazem uso de indicadores da necessidade hídrica, além da grande variação na dotação de rega para a planta e em geral as lâminas são fixas do inicio até o final do ciclo de desenvolvimento.

Neste contexto, objetivou-se avaliar a influência da adubação potássica, lâmina de água e intervalo de irrigação no progresso de doenças fúngicas e produtividade da melancia.

\section{MATERIAL E MÉTODOS}

Foram conduzidos dois ensaios em condições de campo com histórico de plantio de melancia, na estação experimental da Universidade Federal do Tocantins, município de Gurupi-TO, nos anos de 2009 e 2010. Para o maior controle local e com o propósito de se verificar a influência do clima sobre os tratamentos e também no desenvolvimento das doenças durante a condução dos ensaios foram monitoradas as variáveis climáticas como precipitação (mm), temperaturas $\left({ }^{\circ} \mathrm{C}\right)$ e umidade relativa do ar (\%).

\section{Ensaio I - Influência da adubação} potássica no progresso do crestamento gomoso e na produtividade da melancia

$\mathrm{O}$ ensaio foi conduzido durante a estação chuvosa no período de setembro a novembro de 2009. O solo foi classificado como Latossolo Vermelho Amarelo Distrófico (LVAd), de acordo com Embrapa (2006) e com as seguintes características químicas antes da adubação: $\mathrm{pH}\left(\mathrm{CaCl}_{2}\right)=5,0 ; \mathrm{P}=3,7 \mathrm{mg} /$ $\mathrm{dm}^{3}$ (Mehlich); matéria orgânica $=16,1$ $\mathrm{g} / \mathrm{dm}^{3} ; \mathrm{K}=6,2 \mathrm{mg} / \mathrm{dm}^{3}$ (Mehlich); $\mathrm{Ca}+$ $\mathrm{Mg}=2,7 \mathrm{cmol} / \mathrm{dm}^{3} ; \mathrm{Al}=0,0 \mathrm{cmol} / \mathrm{dm}^{3} ; \mathrm{H}$ $+\mathrm{Al}=1,8 \mathrm{cmol} / \mathrm{dm}^{3}$. O preparo do solo foi feito com duas gradagens cruzadas para o destorroamento e nivelamento, usando-se uma grade leve de discos. Para a adubação na base aplicou-se $850 \mathrm{~kg} \mathrm{ha}^{-1}$ da formulação 05-25-15 de NPK, e em cobertura aos 25 dias após o transplantio (DAT), com $40 \mathrm{~kg}$ de nitrogênio, na forma de uréia, em todos os tratamentos.

A semeadura foi realizada em copo plástico contendo uma mistura de esterco bovino curtido, subsolo e substrato comercial Plantmax $^{\circledR}$, na proporção de 1:2:1. As plântulas foram mantidas com irrigação diária, conforme a necessidade, sob condições de casa de vegetação. Utilizou-se a cultivar Crimson Sweet, por ser muito plantada no Brasil e bem aceita pelo mercado consumidor, apesar de ser suscetível às principais doenças (Santos et al., 2009). Após 15 dias da semeadura, as mudas foram transplantadas para o campo, em covas com espaçamento de 2 × $2 \mathrm{~m}$, deixando-se no final apenas duas plantas/cova.

Utilizou-se o delineamento experimental de blocos ao acaso com três tratamentos e 12 repetições, com um total de 32 parcelas. Os tratamentos constituíram-se nas doses 0,50 e 100 $\mathrm{kg} \mathrm{ha}^{-1}$ de cloreto de potássio $(\mathrm{KCl})$ aplicados de uma só vez aos 25 DAT.
Não foram realizadas pulverizações de fungicidas para o controle de doenças. O controle de plantas daninhas foi feito de forma manual, com enxadas aos 20 e 30 DAT. O controle das pragas foi realizado com pulverizações dos inseticidas deltrametrina $(100 \mathrm{~mL} / 100 \mathrm{~L}$ de água) e acefato (100 mL/100L de água) aos $15,20,25$ e 35 DAT.

Todas as parcelas foram irrigadas uniformemente até os 30 DAT, devido ao início das chuvas, e posteriormente nos dias onde não houve precipitação. Utilizou-se sistema por aspersão convencional com turno de rega de $12 \mathrm{~h}$ (20 minutos de irrigação pela manhã e 20 minutos ao final da tarde), para evitar os horários de ventos fortes. A lâmina media de água foi de $7,9 \mathrm{~mm}$ por dia, medida por coletores colocados no centro de cada parcela.

A avaliação da severidade foi iniciada quando os primeiros sintomas do crestamento gomoso apareceram nas folhas. A etiologia da doença foi confirmada a partir da coleta de folhas com sintomas e observação dos sinais (picnídios) em laboratório. A severidade da doença foi quantificada por meio da escala de notas, adotada por Santos \& Café-Filho (2005) $(0=$ planta sadia; $1=$ $>1 \%$ da área foliar afetada; $3=1$ a 5\% da área foliar afetada; $5=6$ a $25 \%$ da área foliar doente; $7=26-50 \%$ da folha doente; $9=>50 \%$ da área foliar afetada). Para obtenção das curvas de progresso da doença em cada tratamento, as notas atribuídas foram convertidas para porcentagens de área foliar infectada pelo ponto médio de cada nota, em cada uma das parcelas estudadas aos 46, 50, 56, 60 e 64 DAT. Após a obtenção das curvas de progresso em cada tratamento, calcularam-se os valores da Área Abaixo da Curva de Progresso da Doença (AACPD) através do programa SigmaPlot versão 11.0, através da equação citada por Shaner \& Finney (1977).

A colheita e pesagem dos frutos foi realizada aos 70 DAT, quando observou-se a maturação dos frutos. As características avaliadas foram número e peso médio de frutos por parcela. Para se obter as características relacionadas à qualidade dos frutos utilizou-se o suco da polpa e foram avaliados o $\mathrm{pH}$, através do pH-metro digital; sólidos 
solúveis totais em $\%$ de ${ }^{\circ}$ Brix (SS), por refratometria e acidez total titulável em $\%$ de ácido málico (ATT), obtida pela titulação com $\mathrm{NaOH}$ a $0,01 \mathrm{~N}$ sobre a diluição de $2 \mathrm{~mL}$ de suco da polpa em $10 \mathrm{~mL}$ de água destilada, usando como indicador fenolftaleína. Além destas, também foi calculada a relação teor de sólidos solúveis/acidez total titulável (Ratio) para avaliar o estado de maturação dos frutos.

Foram ajustados modelos de regressão para as curvas de progresso da doença, e os dados obtidos da AACPD e os dados de produção e qualidade foram submetidos à análise de variância, utilizando-se o teste F, e a comparação das médias foi feita pelo teste de Tukey $(\mathrm{p}=0,05)$, utilizando programa estatístico SISVAR, 5.1 Build 72.

Ensaio II - Influência da lâmina de água e intervalo de irrigação no progresso do míldio e produtividade da melancia

O ensaio foi conduzido em 2010, em campo da UFT de Gurupi, nos meses de maio a julho, na estação seca, sem ocorrência de precipitação. O preparo do solo foi realizado com a mesma metodologia descrita no ensaio anterior.

O delineamento experimental foi de blocos ao acaso, em esquema fatorial de $3 \times 3$, sendo o fator a correspondente a três lâminas de irrigação [100, 300 e 500 mm de água aplicados durante o ciclo da cultura (90 dias)], e o fator b a três intervalos de irrigação (diária, a cada dois e três dias), com quatro repetições.

A cultivar Crimson Sweet foi semeada no campo, sendo colocadas cinco sementes por cova. Posteriormente, realizou-se o desbaste deixando-se duas plantas por cova em todas as parcelas. Cada unidade experimental teve área útil constituída de duas fileiras de plantas espaçadas de $2 \times 2$ e $6 \mathrm{~m}$ de comprimento, sendo um total de 16 plantas por parcela. A adubação de base foi feita com 850 $\mathrm{kg} \mathrm{ha}^{-1}$ da formulação 05-25-15 de NPK, e em cobertura $200 \mathrm{~kg}$ de 20-00-20, aos 25 dias após o plantio (DAP). O controle das plantas daninhas e das pragas foi realizado da mesma maneira citada no ensaio I.

A umidade do solo foi acompanhada diariamente, antes da irrigação, através de tensiômetros instalados em cada uma das parcelas, na profundidade de $20 \mathrm{~cm}$. As lâminas de irrigação foram estipuladas a partir da lâmina ideal de 300 mm de água situada na faixa considerada como ideal para a cultura da melancia, que varia de 300 a $400 \mathrm{~mm}$ (Doorenbos \& Kassam, 1994). Desta forma, no presente trabalho, o tratamento com 100 $\mathrm{mm}$ correspondeu à lâmina deficitária e o tratamento com $500 \mathrm{~mm}$ correspondeu à lâmina que excede a necessidade da planta. A água foi colocada de maneira controlada, conforme o tratamento da lâmina na parcela utilizando-se irrigação manual das plantas com regador graduado no período da tarde.

A avaliação da severidade da doença foi feita a partir dos primeiros sintomas visualizados, e realizada por meio da mesma escala de notas descrita no ensaio I, desconsiderando-se o halo amarelado, sendo a etiologia também comprovada em laboratório a partir de folhas com sintomas colhidas nas parcelas e visualização de esporangióforos e esporângios típicos do patógeno. Embora a escala de notas utilizada tenha sido desenvolvida em princípio para o crestamento gomoso, esta foi adaptada para também avaliar a severidade do míldio, conforme sugerido por Santos et al. (2009), já que o míldio também é uma doença foliar que causa necroses nas folhas. Para obtenção das curvas de progresso da doença em cada tratamento, as notas atribuídas foram convertidas para porcentagens de área foliar infectada pelo ponto médio de cada nota, em cada uma das parcelas estudadas aos 48 , 53, 58, 63, 68, 73 e 78 DAP. Também foi calculada a AACPD em todos os tratamentos, conforme descrito no ensaio anterior.

A colheita e pesagem dos frutos foi iniciada aos 76 DAP, quando observouse o início da maturação dos frutos, indo até os 90 DAP. Na análise de produção e de seus componentes foram utilizados todos os frutos da área útil das parcelas. As características avaliadas foram o número de frutos comerciais, peso médio de frutos comerciais, produtividade comercial e produtividade total. Os frutos classificados como comerciais foram aqueles livres de danos mecâni- cos, manchas e deformações e com peso superior a 5,0 kg. Para a avaliação dos componentes de qualidade quantificou-se o número de frutos deformados ou tortos, e a análise da qualidade da polpa dos frutos seguiu o mesmo método empregado no ensaio I. Os dados obtidos neste ensaio foram analisados com os mesmos procedimentos estatísticos descritos para o ensaio I.

\section{RESULTADOS E DISCUSSÃO}

\section{Ensaio I - Influência da adubação potássica no progresso do crestamento gomoso e produtividade da melancia}

A presença de chuvas a partir de 40 DAT tornou o ambiente propício ao surgimento de doenças, devido ao aumento da umidade relativa do ar e presença de inóculo no local do experimento. Durante a condução do ensaio, a precipitação acumulada nos meses de setembro, outubro e novembro foram respectivamente 71,2, 242,4 e $120 \mathrm{~mm}$ de água. A temperatura variou de 28 a $38^{\circ} \mathrm{C}$ e a umidade relativa do ar de 40 a $90 \%$.

A partir de 46 DAT, todos os tratamentos já evidenciavam o início dos sintomas do crestamento gomoso nas folhas, caracterizados por manchas circulares de coloração marrom-escura rodeadas por um halo necrótico. O progresso da doença observado a partir deste período tornou-se exponencial em todos os tratamentos até os 64 DAT (Figura 1), sendo que o ajuste da curva de progresso da doença obtido foi significativo ao nível de $1 \%$, conforme Little \& Hills (1978). Não houve diferença significativa entre os tratamentos para os valores da AACPCG (Tabela 1), demonstrando a não influência das doses de potássio aplicadas na severidade da doença.

Observou-se que as chuvas contínuas favoreceram a evolução da doença em todas as parcelas experimentais independente dos tratamentos utilizados. Este fato pode estar relacionado à fácil disseminação do patógeno $D$. bryoniae por respingos de água, sendo a ocorrência de chuvas e o número de focos por área responsáveis pelo aumento na taxa de progresso da epidemia (Santos et al., 2005a). 
A doença progrediu à medida que as plantas se desenvolveram, alcançando o máximo aos 64 DAT quando se observou mais de $50 \%$ da área foliar afetada na maioria dos tratamentos. Os valores máximos de severidade obtidos foram observados nos tratamentos das doses 0 e $100 \mathrm{~kg} / \mathrm{ha}$ de $\mathrm{KCl}$. Os resultados obtidos neste estudo estão de acordo com os resultados obtidos por Santos et al. (2005a) que, estudando o progresso do crestamento gomoso em plantas de melancia, verificaram que a doença progrediu exponencialmente a partir do 75 DAP, período este correspondente ao início da colheita dos frutos. No entanto, no presente estudo, devido aos altos índices pluviométricos, a doença surgiu mais cedo.

Entre as doses de potássio, não foi observado influência no progresso do crestamento gomoso e não houve uma relação acentuada entre as doses e a severidade da doença. Este resultado está de acordo com Huber \& Arny (1985) que citam que, apesar do potássio ser freqüentemente associado à redução da incidência e severidade de doenças de plantas, este efeito não pode ser generalizado, pois pode variar em função da sua disponibilidade no solo e interação com outros nutrientes, das condições ambientais, da suscetibilidade da planta e do patógeno envolvido. Santos et al. (2005b), estudando o efeito de diferentes doses de nitrogênio em formulação com o potássio (na fórmula 20-00-20, de NPK) em cobertura, no crestamento gomoso do caule da melancia, também constataram que a adubação com estes nutrientes não influenciou na severidade da doença.

As doses de potássio utilizadas não influenciaram significativamente no número e peso médio de frutos (Tabela 2). Provavelmente, sob condições favoráveis de temperatura e umidade, a alta severidade do crestamento gomoso nas plantas contribuiu para os resultados obtidos no presente estudo, como o grande número de frutos podres. Resultado semelhante foi observado por Santos et al. (2009) que relataram perdas de $100 \%$ por doenças, não havendo produção de frutos comerciais em virtude do intenso ataque do crestamento gomoso e do míldio. Costa et al. (2001) também não

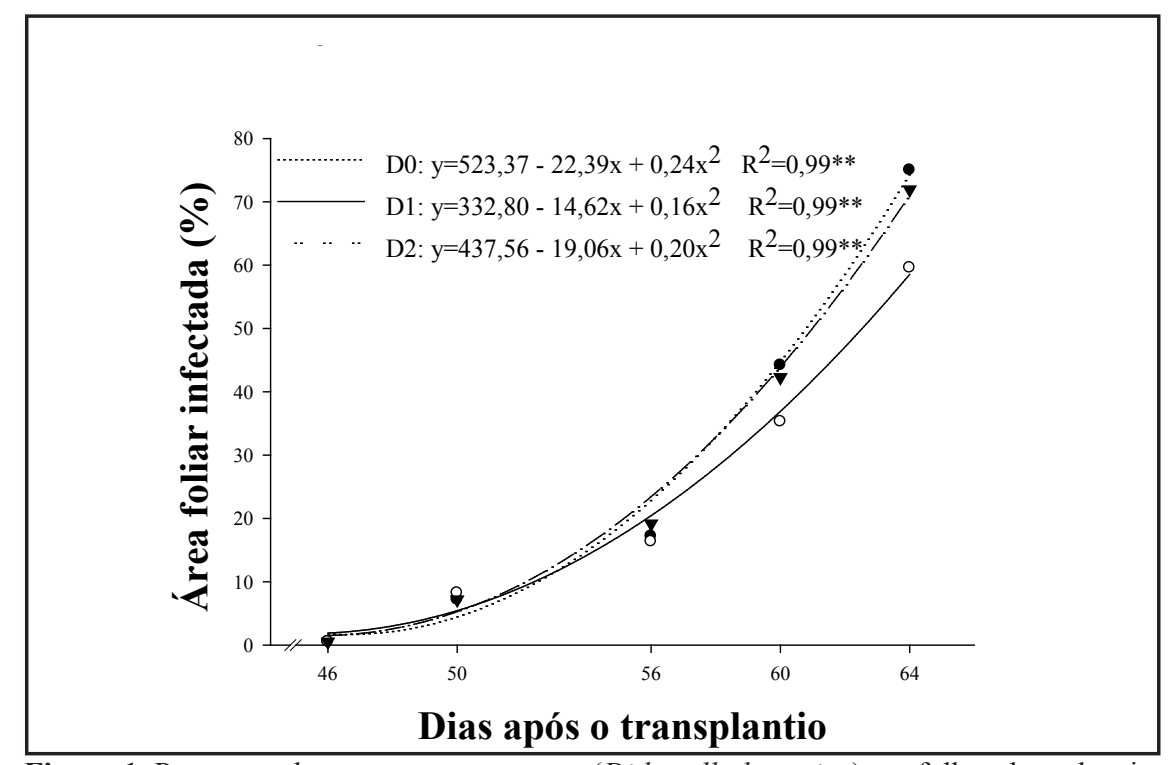

Figura 1. Progresso do crestamento gomoso (Didymella bryoniae) em folhas de melancia, submetida a doses de cloreto de potássio $(\mathrm{KCl})$ aplicado em cobertura (gummy stem blight (Didymella bryoniae) progress in leaves of watermelon subjected to doses of potassium chloride $(\mathrm{KCl})$ applied in side dressing); D0= sem adubação, D1= adubação com $50 \mathrm{~kg}$ $\mathrm{ha}^{-1}$ e D2= adubação com $100 \mathrm{~kg} \mathrm{ha}^{-1}$ (D0= no fertilization, D1= fertilization with $50 \mathrm{~kg}$ ha $^{-1}$ and D2 = fertilization with $\left.100 \mathrm{~kg} \mathrm{ha}^{-1}\right)$;**Nível de significância do modelo ao nível de $1 \%(* *$ significance level of the model at 1\%). Gurupi, UFT, 2009.

constataram diferença na produção de pepinos cultivados em solução nutritiva com diferentes teores de potássio. $\mathrm{O}$ mesmo foi relatado por Viana et al. (2007) ao analisarem a produtividade do meloeiro fertirrigado com potássio em ambiente protegido.

Por outro lado, Costa et al. (2003) observaram aumento no número de frutos de melão fixados devido à redução do abortamento dos frutos, e relataram também que as doses de potássio promoveram o aumento no peso médio do segundo fruto da planta.

A qualidade dos frutos não foi influenciada pelas doses de potássio aplicadas (Tabela 2). Desta forma, não foi observado efeito significativo das diferentes doses de potássio sobre o $\mathrm{pH}$, sólidos solúveis, acidez total titulável e a relação sólidos solúveis/acidez total titulável (Tabela 2). Resultados semelhantes foram obtidos por Costa et al. (2004) em melão e Grangeiro \& Cecílio Filho (2004) em melancia, que também não observaram efeito significativo no teor de sólidos solúveis do suco da polpa dos frutos.

Entre outras possíveis causas da não influência do potássio no progresso da doença e na produção de frutos, está a possível lixiviação deste elemento no solo, pois deve-se considerar que ocorreram altos índices pluviométricos durante a condução do experimento. No entanto, uma adubação potássica adequada, aliado a um manejo da irrigação satisfatório, é desejada para a otimização da produção de melancia.

Ensaio II - Influência da lâmina de água e do intervalo de irrigação no progresso do míldio e na produtividade da melancia

Durante a condução do ensaio II, a temperatura variou de 22 a $34^{\circ} \mathrm{C}$, a umidade relativa do ar de 20 a $60 \%$, registrando-se precipitação de $1,8 \mathrm{~mm}$ que ocorreu apenas no mês de maio. A tensão de água no solo apresentou variações entre as lâminas de água aplicadas, sendo que a tensão média de água no solo no tratamento com a lâmina de 100 $\mathrm{mm}$ foi de $0,66 \mathrm{~atm}, 0,34 \mathrm{~atm}$ na lâmina de $300 \mathrm{~mm}$ e 0,18 atm na lâmina de 500 $\mathrm{mm}$. Estes resultados coletados estão de acordo com o relatado por Doorenbos \& Kassam (1994). Segundo estes autores, para a maioria das cucurbitáceas, a irrigação aplicada pode ser considerada insuficiente se a tensão critica de água no solo estiver em torno de 0,49 a $0,78 \mathrm{~atm}$. 
Devido ao gradiente térmico provocado pelas altas temperaturas diárias e baixas temperaturas noturnas, ocorreu molhamento foliar principalmente à noite. Estas condições, associadas à umidade proporcionada pela irrigação, favoreceram o desenvolvimento do míldio. Os primeiros sintomas de míldio foram observados aos 48 DAP, quando nas folhas observou-se sintomas de manchas amareladas na parte superior e encharcadas na parte inferior. Estas manchas, com a evolução da doença, tornaram-se necróticas e com halo amarelado.

Até aos 63 DAP foi possível observar que o progresso da doença nas folhas aumentou de maneira linear em todos os tratamentos avaliados. A partir de 58 DAP, as curvas de progresso apresentaram forma exponencial nas plantas mantidas com lâminas de irrigação de 300 e $500 \mathrm{~mm}$ de água e mais tarde a partir dos 68 DAP nas plantas mantidas com o tratamento da lâmina de $100 \mathrm{~mm}$ de água (Figura 2). O modelo exponencial de ajuste das curvas foi significativo ao nível de 1\% (Little \& Hills, 1978). O aumento da doença a partir dos 58 DAP, observado nas plantas mantidas com lâmina de irrigação de 300 e 500 $\mathrm{mm}$ pode estar relacionado à umidade elevada propiciada pelas lâminas de irrigação e o maior adensamento das folhas. A evolução da infecção por $P$. cubensis é dependente de água, seja de orvalho ou de chuvas intermitentes, bem como temperaturas amenas e umidade relativa elevada (Terao et al., 2008). Quando encontram condições propícias, os zoósporos nadam sobre as folhas e penetram através dos estômatos, iniciando a infecção (Thomas, 1996).

De acordo com a AACPM (Tabela 1), as lâminas de irrigação influenciaram no progresso do míldio, sendo que os maiores valores da AACPM observados, ocorreram no tratamento com a lâmina de $500 \mathrm{~mm}$ e o menor valor na lâmina de $100 \mathrm{~mm}$.

No tratamento onde as plantas foram mantidas com lâmina de irrigação de $100 \mathrm{~mm}$ de água, o progresso da doença se intensificou apenas a partir dos 68 DAP, apresentando ao final do ciclo $12,37 \%$ de área foliar doente em todos os intervalos de irrigação. $\mathrm{O}$ fato de a se- veridade ter sido baixa neste tratamento, pode estar relacionado ao menor volume de área foliar desenvolvido. Neste tratamento houve menor área sombreada, o ar provavelmente circulou com mais facilidade, havendo maior evaporação e evapo-transpiração no solo e na planta, respectivamente. Estas condições associadas ao menor suprimento de água do tratamento permitiram a menor severidade da doença (Figura 2A). Pivonia et al. (2004), ao analisarem o efeito de diferentes regimes de irrigação na expressão da doença "colapso do meloeiro" causado por Monosporascus cannonballus, observaram que a menor freqüência de irrigação diminuiu a incidência da doença, mas reduziu também

Tabela 1. Área abaixo da curva de progresso de doença, do crestamento gomoso (AACPCG) e míldio (AACPM), em folhas de melancia, em função de diferentes doses de potássio, lâminas de irrigação e intervalos de irrigação (area below the curve of progress of gummy stem blight (AACPCG) and downy mildew (AACPM) in leaves of watermelon, depending on doses of potassium, of irrigation levels and irrigation interval). Gurupi, UFT, 2009.

\begin{tabular}{|c|c|c|c|}
\hline Doses de potássio (kg/ha) & \multicolumn{3}{|c|}{$\mathbf{A A C P C G}^{1}$} \\
\hline 0 & \multicolumn{3}{|c|}{$443,5 \mathrm{a}$} \\
\hline 50 & \multicolumn{3}{|c|}{454,9 a } \\
\hline 100 & \multicolumn{3}{|c|}{$376,5 \mathrm{a}$} \\
\hline CV (\%) & \multicolumn{3}{|c|}{26,26} \\
\hline & \multicolumn{3}{|c|}{ AACPM $^{1}$ (intervalos de irrigação) ${ }^{3}$} \\
\hline${\text { Lâmina de água }{ }^{2}}^{2}$ & In 1 & In 2 & In 3 \\
\hline $\mathrm{L} 1(100 \mathrm{~mm})$ & $63,75 \mathrm{aA}^{4}$ & $60,50 \mathrm{bA}$ & $57,25 \mathrm{bA}$ \\
\hline L2 (300mm) & $130,50 \mathrm{aA}$ & $133,75 \mathrm{abA}$ & $194,00 \mathrm{abA}$ \\
\hline L3 $(500 \mathrm{~mm})$ & $101,00 \mathrm{aA}$ & $266,00 \mathrm{aA}$ & $266,00 \mathrm{aA}$ \\
\hline $\mathrm{CV}(\%)$ & \multicolumn{3}{|c|}{30,86} \\
\hline
\end{tabular}

${ }^{\mathrm{T}}$ Médias seguidas de mesma letra, não diferem entre si, pelo teste de Tukey, ao nível de $5 \%$ de probabilidade (averages followed by same letter do not differ by Tukey test at $5 \%$ probability); ${ }^{2}$ Lâminas de irrigação: $\mathrm{L} 1=100 \mathrm{~mm}$ de água; $\mathrm{L} 2=300 \mathrm{~mm}$ de água e L3 $=500$ mm de água ( ${ }^{2}$ water levels: $\mathrm{L} 1=100 \mathrm{~mm}$ of water, $\mathrm{L} 2=300 \mathrm{~mm}$ of water and L3 $=500 \mathrm{~mm}$ of water); ${ }^{3}$ Intervalos de irrigação: In 1= irrigação diária; In $2=$ irrigação a cada dois dias e In $3=$ irrigação a cada três dias ( ${ }^{3}$ irrigation intervals: In $1=$ daily irrigation; In $2=$ irrigation every two days and In $3=$ irrigation every three days); ${ }^{4}$ Dados originais foram transformados para $\sqrt{\mathrm{x}+1}$, visando obter homogeneidade de variância e submetidos à análise de variância ( ${ }^{4}$ original data were transformed to $\sqrt{\mathrm{x}+1}$ to obtain homogeneity of variance and subjected to analysis of variance).

Tabela 2. Médias do número (NMF) e peso médio dos frutos (PMF), e componentes de qualidade do suco da polpa: pH, teor de sólidos solúveis (SS), acidez total titulável (ATT) e relação de sólidos solúveis/acidez total titulável (RATIO) de frutos de melancia, em função de diferentes doses de potássio (averages ${ }^{1}$ number (NMF) and fruit average weight (PMF), and components of quality of juice from the pulp: $\mathrm{pH}$, soluble solids content, total titratable acidity (ATT) and ratio of soluble solids/total titratable acidity (RATIO) of watermelon fruits, depending on different doses of potassium). UFT, Gurupi, 2009.

\begin{tabular}{lcccccc}
\hline \multirow{2}{*}{$\begin{array}{l}\text { Doses de potássio } \\
\left.\mathbf{( k g ~ h a}^{-1}\right)\end{array}$} & \multirow{2}{*}{$\mathbf{N M F}^{1}$} & PMF & \multicolumn{5}{c}{ Componentes de qualidade dos frutos } \\
\cline { 5 - 7 } & & $\mathbf{p H}$ & $\mathbf{S S}$ & $\mathbf{A T T}$ & $\mathbf{R A T I O}$ \\
\hline 0 & $2,06 \mathrm{a}$ & $5,66 \mathrm{a}$ & $5,00 \mathrm{a}$ & $7,58 \mathrm{a}$ & $0,09 \mathrm{a}$ & $76,50 \mathrm{a}$ \\
50 & $1,91 \mathrm{a}$ & $6,08 \mathrm{a}$ & $5,08 \mathrm{a}$ & $6,50 \mathrm{a}$ & $0,10 \mathrm{a}$ & $65,16 \mathrm{a}$ \\
100 & $1,95 \mathrm{a}$ & $5,33 \mathrm{a}$ & $5,08 \mathrm{a}$ & $7,16 \mathrm{a}$ & $0,09 \mathrm{a}$ & $71,00 \mathrm{a}$ \\
\hline $\mathrm{CV}(\%)$ & 17,64 & 18,32 & 4,77 & 16,56 & 11,90 & 31,54 \\
\hline
\end{tabular}

Médias seguidas de mesma letra, não diferem entre si, pelo teste de Tukey, ao nível de $5 \%$ de probabilidade (averages followed by same letter do not differ by Tukey test at 5\% probability); ${ }^{1}$ Dados originais foram transformados para $\sqrt{\mathrm{x}+1}$, visando obter homogeneidade de variância e submetidos à análise de variância ( ${ }^{1}$ original data were transformed to $\sqrt{\mathrm{x}+1}$ to obtain homogeneity of variance and subjected to analysis of variance). 


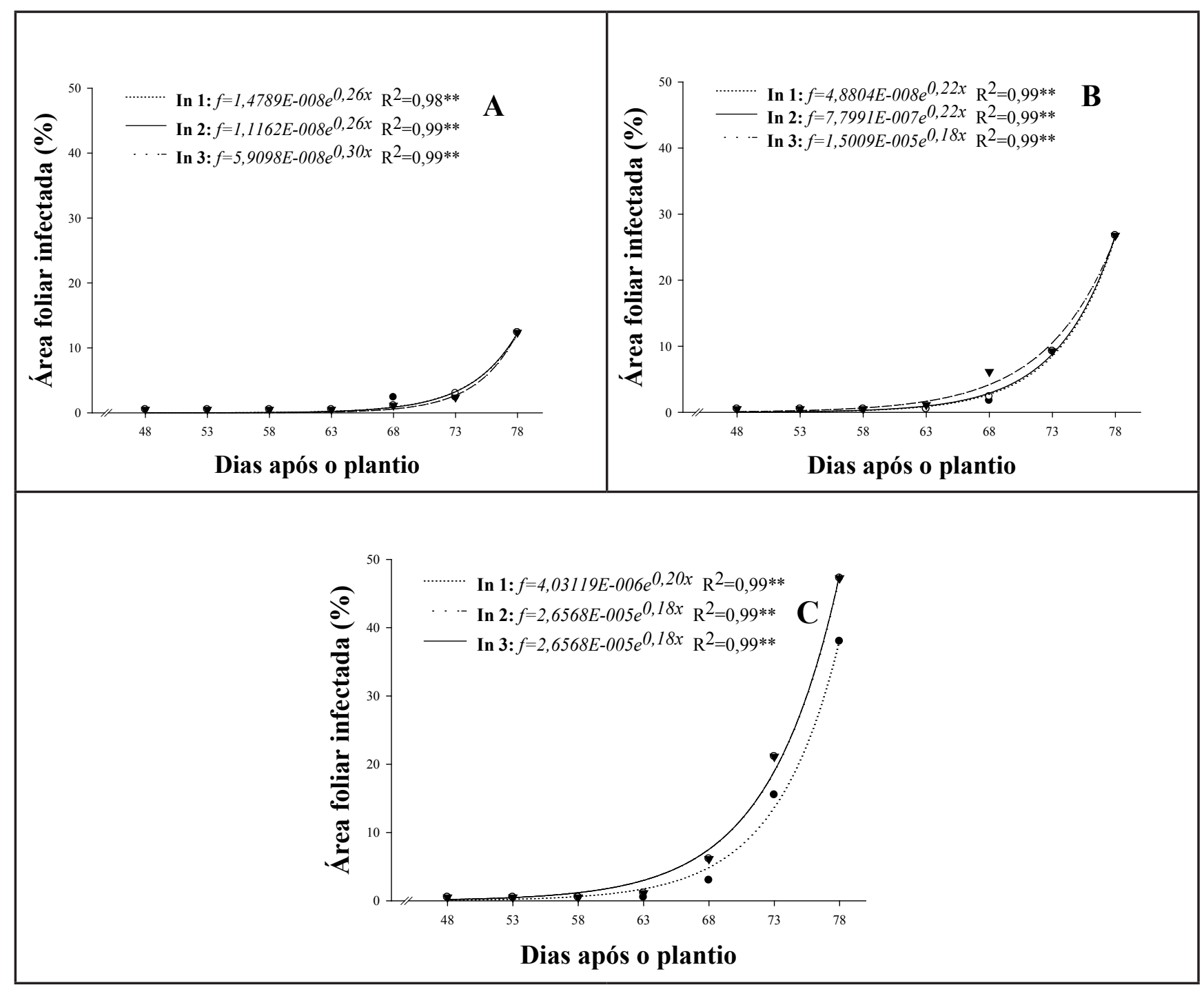

Figura 2. Progresso do míldio (Pseudoperonospora cubensis) em folhas de melancia, submetidas a diferentes lâminas de irrigação (A= $100 \mathrm{~mm}$ de água, $\mathrm{B}=300 \mathrm{~mm}$ de água e $\mathrm{C}=500 \mathrm{~mm}$ de água) associadas a intervalos de irrigação (In $1=$ irrigação diária, In $2=$ irrigação a cada dois dias e In 3 = irrigação a cada três dias) (progress of downy mildew (P. cubensis) in leaves of watermelon, under different irrigation levels $(\mathrm{A}=100 \mathrm{~mm}$ of water, $\mathrm{B}=300 \mathrm{~mm}$ of water and $\mathrm{C}=500 \mathrm{~mm}$ of water) associated to irrigation intervals (In $1=$ daily irrigation, In $2=$ Irrigation every two days and 3 = irrigation every three days); **Nível de significância estatística do modelo, ao nível de $1 \%$, com dois graus de liberdade (**statistical significance level of the model at 1\%), with two degrees of freedom). Gurupi, UFT, 2010.

a produtividade e qualidade dos frutos, devido à escassez de água.

Nas plantas mantidas com a lâmina de irrigação de $300 \mathrm{~mm}$ de água (Figura 2B), observou-se que o progresso da doença se intensificou a partir dos 58 DAP em todos os intervalos de irrigação aplicados. O intervalo de irrigação a cada três dias propiciou progresso levemente superior aos demais até os 75 DAP. Entretanto, ao final do ciclo da cultura, todos os intervalos apresentaram mais de $25 \%$ da área foliar doente, demonstrando que a doença alcançou níveis mais elevados ao final do ciclo independente da freqüência da irrigação.
No tratamento com a lâmina de irrigação de $500 \mathrm{~mm}$ de água (Figura 2C), foi possível notar que a partir de 58 DAP o progresso do míldio se intensificou até os 78 DAP. No intervalo de irrigação diária foram observados níveis inferiores de severidade $(38 \%$ de área foliar doente). Os intervalos de irrigação a cada dois e três dias proporcionaram maiores médias de severidade da doença, apresentando $47,5 \%$ de área foliar doente ao final do ciclo. É provável que o maior porte das plantas, maior sombreamento associado ao maior acúmulo de água nas folhas, proporcionou menor circulação de ar sob o dossel.
Estas condições aumentaram a umidade e tornaram o ambiente favorável ao desenvolvimento da doença. Cardoso et al. (2002) cita que o míldio é uma doença de progresso rápido, que sob condições de umidade relativa elevada e água livre nas folhas, pode reduzir, rapidamente a área foliar e, consequentemente, a fotossíntese, provocando danos à produção. Segundo esses autores, outro fator que pode estar relacionado à maior severidade da doença, pode ser em função das mudanças estruturais nas folhas, que podem ser determinadas pelo excesso de água. Apesar dos elevados níveis de severidade do míldio observados, a 
Tabela 3. Médias do número (NFC) e peso médio dos frutos comerciais (PMFC), produtividade comercial (PC) e produtividade total em $\mathrm{t} \mathrm{ha}^{-1}(\mathrm{PT})$ de frutos de melancia, em função de diferentes lâminas de irrigação e intervalo de irrigação (average number (NFC) and fruit commercial average weight (PMFC), commercial productivity (PC) and total yield in tha ${ }^{-1}(\mathrm{PT})$ of watermelon fruits, depending on different irrigation levels and irrigation intervals). Gurupi, UFT, 2010.

\begin{tabular}{|c|c|c|c|c|c|}
\hline \multicolumn{2}{|c|}{$\begin{array}{l}\text { Tratamentos } \\
\end{array}$} & \multirow{2}{*}{ NFC } & \multirow{2}{*}{ PMFC $^{3}$} & \multirow{2}{*}{$\mathbf{P C}^{3}$} & \multirow{2}{*}{ PT } \\
\hline Lâmina de água & Intervalo de irrigação & & & & \\
\hline \multirow{3}{*}{ L1 $(100 \mathrm{~mm})^{1}$} & $\operatorname{In} 1^{2}$ & $13,75 \mathrm{a}$ & $5,0 \mathrm{a}$ & $6,75 \mathrm{~b}$ & $12,00 \mathrm{~b}$ \\
\hline & In 2 & $14,00 \mathrm{a}$ & $5,0 \mathrm{a}$ & $5,75 \mathrm{~b}$ & $13,50 \mathrm{~b}$ \\
\hline & In 3 & $13,50 \mathrm{a}$ & $6,5 \mathrm{a}$ & $4,75 \mathrm{~b}$ & $11,75 \mathrm{~b}$ \\
\hline Média $^{4}$ & & $13,75 \mathrm{~b}$ & $5,5 \mathrm{~b}$ & $5,75 \mathrm{~b}$ & $12,41 \mathrm{~b}$ \\
\hline \multirow{3}{*}{ L2 (300mm) } & In 1 & $15,75 \mathrm{a}$ & $7,50 \mathrm{a}$ & $13,75 \mathrm{ab}$ & $21,25 \mathrm{a}$ \\
\hline & In 2 & $16,75 \mathrm{a}$ & $7,25 \mathrm{a}$ & $15,50 \mathrm{ab}$ & $23,25 \mathrm{a}$ \\
\hline & In 3 & $15,50 \mathrm{a}$ & $6,75 \mathrm{a}$ & $10,00 \mathrm{ab}$ & $18,50 \mathrm{ab}$ \\
\hline Média & & $16,08 \mathrm{a}$ & $7,16 \mathrm{ab}$ & $13,08 \mathrm{a}$ & $21,00 \mathrm{a}$ \\
\hline \multirow{3}{*}{ L3 (500mm) } & In 1 & $15,75 \mathrm{a}$ & $7,25 \mathrm{a}$ & $18,00 \mathrm{a}$ & $23,50 \mathrm{a}$ \\
\hline & In 2 & $17,00 \mathrm{a}$ & $7,25 \mathrm{a}$ & $21,50 \mathrm{a}$ & $26,00 \mathrm{a}$ \\
\hline & In 3 & $17,00 \mathrm{a}$ & $7,50 \mathrm{a}$ & $17,00 \mathrm{a}$ & $24,35 \mathrm{a}$ \\
\hline Média & & $16,50 \mathrm{a}$ & $7,33 \mathrm{a}$ & $18,83 \mathrm{a}$ & $24,58 \mathrm{a}$ \\
\hline $\mathrm{CV}(\%)$ & & 13,8 & 15,61 & 26,96 & 24,07 \\
\hline
\end{tabular}

Médias seguidas de mesma letra na coluna, não diferem entre si, pelo teste de Tukey, ao nível de 5\% de probabilidade (averages followed by same letter in column do not differ by Tukey test at 5\% probability); ${ }^{1}$ Lâminas de irrigação: L1= $100 \mathrm{~mm}$ de água; L2=300 mm de água e L3= $500 \mathrm{~mm}$ de água ( ${ }^{1}$ water levels: $\mathrm{L} 1=100 \mathrm{~mm}$ of water, L2=300 $\mathrm{mm}$ of water and L3= $500 \mathrm{~mm}$ of water); ${ }^{2}$ Intervalos de irrigação: In $1=$ irrigação diária; In 2= irrigação a cada dois dias e In 3= irrigação a cada três dias ( ${ }^{2}$ irrigation intervals: In $1=$ daily irrigation; In $2=$ irrigation every two days and In $3=$ irrigation every three days); ${ }^{3}$ Dados originais foram transformados para $\sqrt{\mathrm{x}+1}$, visando obter homogeneidade de variância e submetidos à análise de variância ( ${ }^{3}$ original data were transformed to $\sqrt{\mathrm{x}+1}$ to obtain homogeneity of variance and subjected to analysis of variance); ${ }^{4}$ Médias dos tratamentos de lâminas de irrigação ( ${ }^{4}$ average treatments of irrigation levels).

produção foi crescente com o aumento nas lâminas de irrigação (Tabela 3 e 4).

Não se observou diferença significativa do número e peso médio de frutos comerciais dentre os intervalos de irrigação testados. Entretanto, houve diferença significativa nos valores médios de frutos comerciais e peso médio dos frutos verificados em função da lâmina de irrigação (Tabela 3). Na lâmina de $100 \mathrm{~mm}$ foram constatadas menores médias de número de frutos $(13,75$ frutos) e peso médio dos frutos comerciais $(5,5 \mathrm{~kg})$. Possivelmente, esta diminuição do número de frutos foi devido ao crescimento inferior da planta proporcionado por este tratamento de lâmina deficitária. Azevedo et al. (2005) relatam que a deficiência hídrica causa um decréscimo acentuado nas atividades fisiológicas, principalmente na divisão e no crescimento das células e, em conseqüência, no crescimento e produção das plantas. Resultado semelhante ao obtido neste estudo foi observado por Medeiros et al. (2007) que, ao analisarem a influência de lâminas de irrigação na produção de melão Cantaloupe, observaram que a redução da lâmina de irrigação determinou a diminuição do número de frutos totais e o número de frutos para o mercado interno.

Em relação à produtividade comercial, o tratamento de plantas mantidas com lâmina de irrigação de $500 \mathrm{~mm}$ de água proporcionou produtividade superior aos demais tratamentos (Tabela 3). Houve um acréscimo de $13,08 \mathrm{tha}^{-1}$ com relação à produtividade comercial verificada na lâmina de $100 \mathrm{~mm}$. A maior média de produtividade de frutos comerciais foi de 21,50 $\mathrm{tha}^{-1}$ observada na lâmina de irrigação de $500 \mathrm{~mm}$ e o menor valor da produtividade foi de 4,75 t ha ${ }^{-1}$ na lâmina de $100 \mathrm{~mm}$ de água.

A maior produtividade total foi verificada nas parcelas com a aplicação da lâmina de irrigação de $500 \mathrm{~mm}$ de água (Tabela 3). Os tratamentos de intervalos de irrigação diária e a cada dois dias da lâmina de irrigação de 300 $\mathrm{mm}$ de água proporcionaram média de produtividade total de 21,25 e $23,25 \mathrm{t}$ ha $^{-1}$ respectivamente, não diferindo do tratamento da lâmina de $500 \mathrm{~mm}$ de água. A maior produtividade total foi de 26,00 tha ${ }^{-1}$, observado no tratamento da lâmina de $500 \mathrm{~mm}$ de água e o menor valor foi de $11,75 \mathrm{t} \mathrm{ha}^{-1}$ no tratamento da lâmina de $100 \mathrm{~mm}$ de água. Os resultados obtidos neste trabalho estão de acordo com Araújo et al. (2010). Segundo estes autores ao estudarem o efeito de diferentes níveis de irrigação na cultura do meloeiro, observaram que houve uma relação linear crescente da produtividade de frutos de acordo com o aumento nos níveis de irrigação.

Com relação às características relacionadas à qualidade dos frutos avaliados, foi observada diferença significativa do número de frutos deformados ou tortos (Tabela 4), sendo as maiores médias verificadas no tratamento da lâmina de $100 \mathrm{~mm}$ de água ( 9,83 frutos) e as menores médias observadas no tratamento da lâmina de $500 \mathrm{~mm}$ de água (1,16 frutos). A deformação de frutos pode ser devido a vários fatores, sendo atribuída principalmente à deficiência hídrica, deficiência de boro e má poli- 
Tabela 4. Médias do número de frutos deformados por parcela (FD) e componentes de qualidade do suco da polpa: pH, teor de sólidos solúveis (SS), acidez total titulável (ATT) e relação de sólidos solúveis e acidez total titulável (RATIO) de frutos de melancia em função de diferentes lâminas de irrigação e intervalo de irrigação (average number of deformed fruits per plot (FD) and components of quality of juice from the pulp: $\mathrm{pH}$, soluble solids content (SS), total titratable acidity (ATT) and ratio of soluble solids/total titratable acidity (RATIO) of watermelon fruits, cv. Crimson Sweet, depending on different irrigation levels and irrigation interval). Gurupi, UFT, 2010.

\begin{tabular}{|c|c|c|c|c|c|c|}
\hline \multicolumn{2}{|c|}{ Tratamentos } & \multirow{2}{*}{$\mathbf{F D}^{3}$} & \multirow{2}{*}{ pH } & \multirow{2}{*}{ SS } & \multirow{2}{*}{ ATT } & \multirow{2}{*}{ RATIO } \\
\hline Lâmina de água & Intervalo de irrigação & & & & & \\
\hline \multirow{3}{*}{$\mathrm{L} 1(100 \mathrm{~mm})^{1}$} & $\operatorname{In} 1^{2}$ & $10,25 \mathrm{a}$ & $5,00 \mathrm{a}$ & $9,70 \mathrm{a}$ & $0,095 \mathrm{a}$ & $106,50 \mathrm{a}$ \\
\hline & In 2 & $10,00 \mathrm{a}$ & $5,00 \mathrm{a}$ & $10,75 \mathrm{a}$ & $0,980 \mathrm{a}$ & $110,75 \mathrm{a}$ \\
\hline & In 3 & $9,25 \mathrm{a}$ & $5,00 \mathrm{a}$ & $10,00 \mathrm{a}$ & $0,940 \mathrm{a}$ & $106,50 \mathrm{a}$ \\
\hline \multirow{3}{*}{ L2 (300mm) } & In 1 & $2,75 \mathrm{~b}$ & $5,00 \mathrm{a}$ & $8,75 \mathrm{a}$ & $0,100 \mathrm{a}$ & $88,50 \mathrm{a}$ \\
\hline & In 2 & $2,25 \mathrm{~b}$ & $5,00 \mathrm{a}$ & $10,25 \mathrm{a}$ & $0,100 \mathrm{a}$ & $100,25 \mathrm{a}$ \\
\hline & In 3 & $3,00 \mathrm{~b}$ & $5,00 \mathrm{a}$ & $10,00 \mathrm{a}$ & $0,100 \mathrm{a}$ & $99,75 \mathrm{a}$ \\
\hline \multirow{3}{*}{ L3 (500mm) } & In 1 & $1,25 \mathrm{~b}$ & $4,75 \mathrm{a}$ & $9,75 \mathrm{a}$ & $0,090 \mathrm{a}$ & $99,25 \mathrm{a}$ \\
\hline & In 2 & $0,50 \mathrm{~b}$ & $4,75 \mathrm{a}$ & $9,50 \mathrm{a}$ & $0,100 \mathrm{a}$ & $89,75 \mathrm{a}$ \\
\hline & In 3 & $1,75 \mathrm{~b}$ & $4,75 \mathrm{a}$ & $10,50 \mathrm{a}$ & $0,120 \mathrm{a}$ & $88,75 \mathrm{a}$ \\
\hline CV (\%) & & 23,16 & 5,87 & 18,16 & 18,92 & 17,13 \\
\hline
\end{tabular}

Médias seguidas de mesma letra na coluna, não diferem entre si, pelo teste de Tukey, ao nível de 5\% de probabilidade (averages followed by same letter in column do not differ by Tukey test at 5\% probability); ${ }^{1}$ Lâminas de irrigação: $\mathrm{L} 1=100 \mathrm{~mm}$ de água; L2=300 mm de água e L3 = $500 \mathrm{~mm}$ de água ( ${ }^{1}$ water levels: L1 $=100 \mathrm{~mm}$ of water, L2=300 mm of water and L3=500 mm of water); ${ }^{2}$ Intervalos de irrigação: In 1= irrigação diária; In 2= irrigação a cada dois dias e In 3= irrigação a cada três dias ( ${ }^{2}$ irrigation intervals: In 1= daily irrigation; In 2= irrigation every two days and In $3=$ irrigation every three days); ${ }^{3}$ Dados originais foram transformados para $\sqrt{\mathrm{x}+1}$, visando obter homogeneidade de variância e submetidos à análise de variância ( ${ }^{3}$ original data were transformed to $\sqrt{\mathrm{x}+1}$ to obtain homogeneity of variance and subjected to analysis of variance).

nização (Puiatti \& Silva, 2005; Santos et al., 2011). Segundo Thomas (1996), a produção de frutos malformados ou atrofiados pode ser também pela destruição das folhas devido à infecção por P. cubensis.

As características de qualidade do suco da polpa dos frutos de melancia, $\mathrm{pH}$, sólidos solúveis, acidez total titulável e relação sólidos solúveis/acidez total titulável, não foram influenciadas significativamente pelas lâminas e intervalos de irrigação aplicados (Tabela 4). De acordo com o resultado obtido por Cardoso et al. (2002), o aumento da severidade do míldio resulta numa acentuada redução no teor de sólidos solúveis, proporcionando decréscimos de até $49 \%$.

No presente estudo, ficou comprovada a importância do manejo da irrigação no progresso da doença, na produtividade e qualidade dos frutos de melancia. Nesta condição, um manejo adequado, com suprimento de água suficiente para atender as exigências das plantas, poderá atender as expectativas da produção, diminuindo os custos com a irrigação, ao mesmo tempo em que contribui para uma redução na incidência das doenças avaliadas.

\section{AGRADECIMENTOS}

Agradecemos ao CNPq pela bolsa de produtividade em pesquisa concedida ao primeiro autor, e pela bolsa de mestrado concedida ao segundo autor.

\section{REFERÊNCIAS}

ARAÚJO WF; OLIVEIRA GA; CARVALHO FK; SILVA WM; CRUZ PLS; MACIEL FCS. 2010. Manejo da irrigação do meloeiro com base na evaporação do tanque classe A. Horticultura Brasileira 28: 495-499.

AZEVEDO BM; BASTOS FGC; VIANA TVA; RÊGO JL; ÁVILA JHT. 2005. Efeitos de níveis de irrigação na cultura da melancia. Revista Ciência Agronômica 36: 9-15.

CARDOSO JE; SANTOS AA; VIDAL JC. 2002. Efeito do míldio na concentração de sólidos solúveis totais em frutos do meloeiro. Fitopatologia Brasileira 27: 378-383.

CECÍLIO FILHO AB; GRANGEIRO LC. 2004. Produtividade da cultura da melancia em função de fontes e doses de potássio. Ciência e Agrotecnologia 28: 561-569.

COSTACC; CECÍLIO FILHOAB; CAVARIANNI RL; BARBOSA JC. 2003. Produção do melão rendilhado em função da concentração de potássio na solução nutritiva e do número de frutos por planta. Horticultura Brasileira 22: 23-27.

COSTACC; CECÍLIO FILHOAB; CAVARIANNI RL; BARBOSA JC. 2004. Concentração de potássio na solução nutritiva e a qualidade e número de frutos de melão por planta em hidroponia. Ciência Rural 34: 731-736.

COSTA PC; CAÑIZARES KAL; GOTO R. 2001. Produção de pepino de plantas enxertadas cultivadas em soluções nutritivas com diferentes teores de potássio. Horticultura Brasileira 19: 207-209.

DOORENBOS J; KASSAM A H. 1994. Efeito da água no rendimento das culturas. Campina Grande: UFPB. 306 p. (FAO. Irrigação $e$ Drenagem, 33).

EMBRAPA - EMPRESA BRASILEIRA DE PESQUISA AGROPECUÁRIA. 2006. Sistema de classificação dos solos. Brasília: Embrapa Produção de Informações. 306p.

GAMA FR; CASTRO NETO MD; LEÃO EU; GONÇALVES CG; CARDON CH; SARMENTO-BRUM RBC. 2011. Nutrição mineral e adubação na cultura da melancia. In: SANTOS GR; ZAMBOLIM L (eds). Tecnologias para produção sustentável da melancia no Brasil. Visconde do Rio Branco: Suprema Gráfica e Editora LTDA. p. 19-44.

GRANGEIRO LC; CECÍLIO FILHO AB. 2004. Acúmulo e exportação de macronutrientes pelo híbrido de melancia Tide. Horticultura Brasileira 22: 93-97.

HUBER DM; ARNY DC. 1985. Interactions of potassium with plant disease. In: Munson RD 
(ed) Potassium in agriculture. Madison: ASA/ CSSA/SSA. p. 467-488.

LITTLE TM; HILLS FJ. 1978. Agricultural experimentation design and analysis. New York: John Wiley \& Sons. 350p.

MALAVOLTA E. 2005. Potássio: absorção, transporte e redistribuição na planta. In: YAMADA T; ROBERT TL. (eds). Potássio na agricultura brasileira. Piracicaba: Associação Brasileira para Pesquisa da Potassa e do Fosfato. p. 179-238.

MEDEIROS JF; SANTOS SCL; CÂMARA MJT; NEGREIROS MZ. 2007. Produção de melão Cantaloupe influenciado por coberturas do solo, agrotêxtil e lâminas de irrigação. Horticultura Brasileira 25: 538-543.

NACHTIGALL GR; RAIJ BV. 2005. Análise e interpretação do potássio no solo. In: YAMADA T; ROBERTS TL (eds). Potássio na agricultura brasileira. Piracicaba: Associação Brasileira Para Pesquisa da Potassa e do Fosfato. p.179-238.

PIVONIA S; COHEN R; COHEN S; KIGEL J; LEVITA R; KATAN J. 2004. Effect of irrigation regimes on disease expression in melon plants infected with Monosporascus cannonballus. European Journal of Plant Pathology 110: 155-161.

PUIATTI M; SILVA DJH. 2005. Cultura da melancia. In: FONTES PCR. Olericultura teoria e prática. Viçosa: UFV. p 386-406.

SANTOS GR; CAFÉ-FILHO AC. 2005. Reação de genótipos de melancia ao crestamento gomoso do caule. Horticultura Brasileira 23: $945-950$.

SANTOS GR; CAFÉ-FILHO AC; LEÃO FF; CÉSAR M; FERNANDES LE. 2005a. Progresso do crestamento gomoso e perdas na cultura da melancia. Horticultura Brasileira 23: 228-232.

SANTOS GR; CAFÉ-FILHO AC; SABOYA LMF. 2005b. Controle químico do crestamento gomoso do caule em melancia. Fitopatologia Brasileira 30: 155-163.

SANTOS GR; CASTRO NETO MD; ALMEIDA HSM; RAMOS, LN; SARMENTO RA; LIMA SO; ERASMO EAL. 2009. Influência de doses de nitrogênio na severidade de doenças e na produtividade da melancia. Horticultura Brasileira 27: 330-334.

SANTOS GR; CASTRONETO MD; CARVALHO ARS; FIDELIS RR; AFFÉRRI FS. 2010. Fontes e doses de silício na severidade do crestamento gomoso e produtividade da melancia. Bioscience Journal 26: 266-272.

SANTOS GR; CASTRO NETO MD; RAMOS LN; CAFÉ-FILHO AC; REIS A; MOMENTÉ VG; PELÚZIO JM; IGNÁCIO M. 2009. Reaction of melon genotypes to the gummy stem blight and the downy mildew. Horticultura Brasileira 27: 160-165.

SANTOS FJS; LIMA RN; RODRIGUES BHN; CRISÓSTOMO LA; SOUZA F; OLIVEIRA JJG. 2004. Manejo da Irrigação da Melancia:
Uso do Tanque Classe “A”. Fortaleza: Embrapa. 13p. (Circular Técnica da Embrapa Meio Norte, 22).

SANTOS GR; ZAMBOLIM L; COSTA H; CAFÉ-FILHO AC. 2011. Doenças fúngicas, bacterianas e abióticas. In: SANTOS GR; ZAMBOLIM L (eds). Tecnologias para produção sustentável da melancia no Brasil. Visconde do Rio Branco: Suprema Gráfica e Editora LTDA. p. 95-150.

SHANER G; FINNEY RE. 1977. The effect of nitrogen fertilization on the expression of slow-mildewing resistance in Knox wheat. Phytopathology 67: 1051-1056.

SILVA ES. 2010. Porta-enxertos, concentrações de potássio na resistência à Didymella bryoniae e relações fisiológicas do meloeiro. Botucatu: UNESP. 73p (Dissertação mestrado).

TERAO D; VIANA FMP; GUIMARÃES JA; AZEVEDO FR; AMORIM SG. 2008. Manejo integrado de doenças do meloeiro. In: BRAGA SOBRINHO R; GUIMARÃES JA; FREITAS JAD; TERAO D (eds). Produção integrada de melão. Fortaleza: Embrapa Agroindústria Tropical. p. 207-225.

THOMAS CE. 1996. Downy mildew. In: ZITTER TA; HOPKINS DL; THOMAS CE. Compendium of cucurbit diseases. St. Paul: APS Press. p. 25-27.

VIANA TVA; SALES IGM; SOUSA VF; AZEVEDO BM; FURLAN RA; COSTA SC. 2007. Produtividade do meloeiro fertirrigado com potássio em ambiente protegido. Horticultura Brasileira 25: 460-463. 